\title{
PERFIL MICROBIOLÓGICO DE SANDUÍCHES NATURAIS COMERCIALIZADOS NA CIDADE DE JUAZEIRO DO NORTE-CE
}

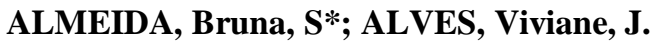 \\ Faculdade Leão Sampaio - Juazeiro do Norte (CE), Brasil.
}

Recebido em: 22/01/2015; Aceito: 22/04/2015; Publicado: 25/08/2015

\section{RESUMO}

Os alimentos naturais são de suma importância para a saúde humana, proporcionando substâncias nutricionais que sofrem pouca interferência de industrializados. Porém a manipulação alimentar e o comércio de rua podem proporcionar contaminação por microrganismos patogênicos e assim causar riscos a saúde do consumidor. O presente estudo teve como objetivo traçar o perfil microbiológico de sanduíches naturais comercializados na cidade de Juazeiro do Norte-CE. Foram coletadas 10 amostras randomizadas em pontos de vendas distintos que comercializassem sanduíches naturais no município de Juazeiro do Norte, com a aplicação de check-list para avaliação das condições higiênico-sanitárias dos locais de vendas. As amostras foram incubadas em meio BHI por 24 horas, posteriormente semeadas nos meios EMB, SS e em meio Ágar Sabouroud, também foram feitas análises parasitológicas pelo método de Hoffman modificado para identificação dos microrganismos encontrados nesse alimento. Os resultados obtidos para analise bacteriológica foram $70 \%$ para Klebsiella spp., 30\% para Escherichia coli e 30\% para Salmonella spp. Para as análises micológicas obteve-se 40\% de contaminação por estruturas leveduriformes, $10 \%$ por bolores e $50 \%$ das amostras apresentaram as duas estruturas bolores e leveduras. Para a analise parasitológica ocorreu a presença de Entamoeba coli, Giardia spp.e Endolimax nana. Conclui-se que as análises do perfil microbiológico de sanduíches naturais foram de importância significativa para contribuir com informações para melhor compreensão das boas práticas de manipulação e higiene alimentar, com isso minimizar os riscos a saúde humana dos que consomem sanduíches naturais.

Palavras-chave: Perfil Microbiológico, Sanduíche, Manipulação, Alimento.

\begin{abstract}
Natural foods are very important for human health, providing nutritional substances that suffer little interference from industrialized. But food handling and the business of street can provide contamination by pathogenic microorganisms and thus cause risks to consumer health. This study aims to trace the microbiological profile of natural sandwiches sold in the city of Juazeiro do Norte-CE. 10 random samples in different points of sales who markets natural sandwiches in Juazeiro do Norte, with the application of a checklist for assessment of hygienic-sanitary conditions of local sales were collected. The samples were incubated in BHI medium for 24 hours, then plated in media EMB agar and SS Sabouroud also parasitological analysis were performed by the method of Hoffman modified to identify the microorganisms found in food. The results obtained for bacteriological examination were $70 \%$ of Klebsiella spp. To $30 \%$ and $30 \%$ for E. coli Salmonella spp. Mycological for analysis was obtained $40 \%$ of the samples were contaminated with yeast structures molds with $10 \%$ and $50 \%$ of the samples were the presence of both yeast and mold structures. For parasitological analysis was the presence of Entamoeba coli, Giardia spp. and Endolimas nails. We conclude that the analysis of the microbiological profile of natural sandwiches were of significant importance to contribute information to better understand the best practices of handling and food hygiene, thus minimizing the risks to human health from consuming natural sandwiches.
\end{abstract}

Keywords: Microbiological, Profile, Sandwich, Handling.

* Bruna Soares de Almeida. Faculdade Leão Sampaio.

Rua Leão XIII, 02, Salesianos - Juazeiro do Norte, Ceará; CEP: 63051280; E-mail: almeidabrunasoares@gmail.com 


\section{INTRODUÇÃO}

Nos últimos anos, os hábitos alimentares da população vêm ingressando em uma nova fase, as mudanças na alimentação populacional estão ganhando outras características, o alimento saudável está sendo incorporada à dieta dos consumidores. Com as mudanças vem à necessidade de alimentos nutritivos, saborosos, porém saudáveis, que não ofereçam risco a saúde ${ }^{1}$.

Com o aumento do hábito de "comer fora" e a necessidade de alimentos rápidos e práticos, o comércio de rua ganha força e com isso os riscos para quem consome esses produtos aumentam significativamente, pois a contaminação dos alimentos por microrganismos está muitas vezes relacionadas com o comércio ambulante e os riscos que as más práticas de manipulação podem causar ${ }^{2}$.

Um dos alimentos mais comercializados por ambulantes e procurados pela população por ser considerado um alimento saudável é o sanduíche natural. O mesmo é composto por ingredientes naturais. As hortaliças, um dos constituintes naturais do sanduíche, quando não higienizadas corretamente podem conter microrganismos patogênicos provenientes do solo como a Salmonella spp. A contaminação pode ser agravada com as más condições de produção, armazenamento, exposição e maus hábitos de higiene do manipulador, expondo o consumidor a riscos de saúde e de contaminação por Doenças Transmitidas por Alimentos (DTA's) ${ }^{3}$.

As DTA's são enfermidades que podem ser causadas por microrganismos patogênicos, quando ingeridos através de alimentos contaminados, podem se manifestar através de infecções, intoxicações, surtos ou casos isolados que podem ocorrer de leves a graves ${ }^{4}$.

As doenças transmitidas por alimentos tornaram-se um problema recorrente nos últimos anos, ficando mais frequente com o aumento populacional e a produção em grande escala de produtos alimentícios para suprir as necessidades da população e seus variados grupos existentes. Consequentemente, o crescimento da ocorrência de DTA's se deve a aspectos como exposição, mudanças de hábito e ambiente, necessidade de consumo rápido e coletivo de alimentos ${ }^{5}$.

Os microrganismos são seres encontrados em todos os lugares, inclusive em alimentos, podendo causar injúrias ao consumidor. Para que ocorra a infecção por microrganismos é necessário à presença de patógenos com sua dose mínima infectante que é a quantidade de células microbianas capazes de provocar a manifestação clínica da doença. As principais bactérias responsáveis por patologias são Staphylococcusaures, Salmonella spp., Shiguella spp., Escherichia coli. Os fungos também são causadores de patologias associadas a alimentos, os principais são Fusarium spp., Aspergillus spp. E Penicillium spp. ${ }^{6}$.

Estudos mostram que a manipulação inadequada dos alimentos é a maior causa de contaminação e surtos no consumo de sanduíches e produtos naturais. Por isso, é necessário o emprego de Boas Práticas (BP) de manipulação alimentar, que são técnicas higiênico-sanitárias como limpeza de mãos, utensílios e ambiente de trabalho. Essas técnicas são utilizadas para proporcionar uma boa qualidade ao alimento a ser consumido, as mesmas estão descritas na Resolução RDC n²16 da ANVISA 2004, com o intuito de evitar a proliferação de microrganismos e consequentemente o aparecimento de surtos de DTA's ${ }^{7,8}$.

Existem sistemas que regularização e norteiam as práticas de segurança alimentar, exemplo desses sistemas são as Boas Práticas (BP) e as Boas Práticas de Fabricação (BPF), controlando todas as etapas de produção, manipulação e transporte de alimentos no intuito de minimizar as contaminações existentes, provenientes do meio ambiente ${ }^{7}$.

Nesse contexto, a comercialização de alimentos prontos, na rua, torna-se um risco para a saúde humana, pois a probabilidade de contaminação alimentar é alta, visto que o processo é realizado de forma artesanal, sem controles específicos, muitas vezes sem uma infraestrutura adequada e sem o conhecimento necessário sobre a manipulação segura dos alimentos.

A preocupação com a boa forma fez despertar a população para uma alimentação saudável, um alimento muito consumido e bastante ofertado no comércio de rua, 
é o sanduíche natural feito com ingredientes naturais como alface e tomate, que por ser produzido de forma manual e com alimentos orgânicos podem estar contaminados por patógenos vindos da matéria-prima ou da má higienização durante a produção ${ }^{8}$.

Por isso, o sanduíche "natural", por ser um alimento comumente comercializado na rua, possuir produção manual e ser composta com uma junção de diferentes tipos de ingredientes, principalmente na forma crua, está propenso a um maior risco de contaminação, tornando-se assim um grave problema para a saúde do homem.

Tomando como base as Boas Práticas de Manipulação, este estudo teve como objetivo traçar o perfil microbiológico de sanduíches naturais comercializados na cidade de Juazeiro do Norte, Ceará. Analisando as condições higiênico-sanitárias dos pontos de vendas, avaliando as praticas dos manipuladores, observando se há presença de microrganismos patogênicos e identificando os possíveis patógenos encontrados nos alimentos estudados.

\section{METODOLOGIA}

\subsection{TIPO E LOCAL DE ESTUDO}

O estudo caracterizou-se por ser do tipo analítico descritivo com abordagem qualitativa, desenvolvido em sanduíches naturais, comercializados no município de Juazeiro do Norte, CE.

\subsection{COLETA DAS AMOSTRAS}

Foram coletadas 10 amostras, em diferentes pontos de venda, que foram escolhidos de forma aleatória. Após a coleta, as amostras foram acondicionadas em isopor com gelo e levadas, o mais rápido possível, para o Laboratório de Microbiologia da Faculdade Leão Sampaio no município de Juazeiro do Norte, Ceará.

\subsection{PREPARAÇÃO DAS AMOSTRAS}

Para realização das análises, foi pesado $20 \mathrm{~g}$ de cada amostra. Separadamente estas amostras foram diluídas em $100 \mathrm{~mL}$ de água destilada estéril e posteriormente, filtrada com auxílio de gaze estéril dobrada quatro vezes.

\subsection{ANÁLISE BACTERIOLÓGICA}

O procedimento para a observação do crescimento e identificação das bactérias foi realizado com base nas normas da Agência Nacional de Vigilância Sanitária (ANVISA). Uma alçada da diluição de cada amostra foi inoculada em meio de enriquecimento Brain Heart Infusion (BHI) e incubada em estufa microbiológica a $37^{\circ} \mathrm{C}$ por $24 \mathrm{~h}$. Em seguida foram semeadas nos meios de culturas Àgar Eosin Methylene Blue (EMB) e Ágar Salmonella-Shigella (SS), com o objetivo de obter uma identificação presuntiva para Escherichia coli, Klebsiella spp., Salmonella e Shigella spp.

\subsection{ANÁLISE MICOLÓGICA}

Para avaliação da presença de fungos foi inoculado uma alçada da diluição de cada amostra em meio Ágar Saboraud e acondicionados em câmara úmida por um período de 5 a 7 dias. Após isso foi observado o crescimento de leveduras e bolores.

A diluição filtrada de cada amostra, também foi submetida à técnica de Hoffman Modificado para análise parasitológica.

\subsection{APLICAÇÃO DE CHECK-LIST}

Paralelamente a análise das amostras obtidas, foi realizado o preenchimento por parte do pesquisador de um check-list com perguntas pertinentes a obtenção da amostra, condições de produção do alimento, local de acondicionamento e manuseio por parte do manipulador de alimentos. 
As análises foram iniciadas nos locais de venda das amostras com o preenchimento do check-list, avaliando as condições higiênico-sanitárias do local e do manipulador, observando assim critérios como local apropriado, uso de Equipamentos de Proteção Individual (EPI's) e preparo higiênico do sanduíche natural.

\section{RESULTADOS E DISCUSSÕES}

A segurança alimentar consiste em critérios básicos para tornar um produto alimentício propício para consumo. Os critérios são determinados pelas normas de produção, características, transporte e armazenamento ${ }^{9}$.

Segundo Sousa ${ }^{10}$, o consumidor a princípio aprecia características como sabor e aroma, que agradem seus olhos e paladar, antes mesmo de pensar na segurança do alimento que está consumindo e apenas em segundo plano fica a exigência sobre a qualidade do produto.

A produção de alimentos seguros implica procedimentos de produção, controle de patógenos e desenvolvimento principalmente de boas práticas de condutas na manipulação dos produtos alimentícios ${ }^{9}$.

No presente estudo foi observado que $100 \%$ dos manipuladores dos sanduíches naturais analisados, não usavam roupas adequadas e não estavam de luvas e $70 \%$ desses manipuladores eram os mesmos que recebiam o dinheiro.

Em estudo semelhante realizado por Aleixo et al., ${ }^{11}$, observou-se que $58 \%$ dos manipuladores de alimentos também eram responsáveis pelo recebimento do dinheiro, que $57 \%$ protegiam os cabelos com uso de touca e que $32 \%$ usavam luvas no momento da produção do alimentos.

Para Ferrari et al. ${ }^{12}$, um alimento seguro consiste em um produto que não provoque danos à saúde, sendo isento de contaminações biológicas, físicas e químicas.

A importância de um local com higiene adequada para a manipulação e produção de alimentos é extremamente necessária para evitar a contaminação e a exposição a risco por parte dos consumidores desses produtos. Segundo Genta, Mauricio e Matioli ${ }^{13}$, na avaliação da higienização dos locais de manipulação de alimentos, o resultado foi de $75 \%$ não estavam de acordo com as normais de higiene no local; em relação ao asseio dos manipuladores $56,3 \%$ possuíam maus hábitos de higiene pessoal.

O manipulador de alimentos é aquele que entra em contato direto ou indireto com o alimento, praticando assim a manipulação alimentar que corresponde ao preparo a partir da matéria-prima até a obtenção do produto final a ser consumido ${ }^{14}$.

O treinamento e a capacitação dos manipuladores de alimentos resultam em efeitos positivos nas boas práticas de manuseio, fazendo com que esses profissionais observem as falhas e passem a evitar as contaminações de serviços alimentares ${ }^{15}$.

Para Campos ${ }^{16}$, a admissão de boas práticas nos dias atuais consiste em um comprometimento dos profissionais, para execução de normas, promovendo o bem-estar e atribuindo qualidade higiênico-sanitária aos alimentos que serão comercializados e consumidos pela população, evitando, através das boas ações, eventuais doenças transmitidas por patógenos encontrados em alimentos contaminados.

No presente estudo foi possível observar que $60 \%$ dos sanduíches naturais eram produzidos na hora, $70 \%$ eram acondicionadas em local adequado e $70 \%$ estavam embaladas por papel filme.

De acordo com Oliveira et al., ${ }^{17}$ as más práticas de manipulação, armazenamento e refrigeração de produtos alimentícios, são as principais causas do aumento de DTA's nos últimos tempos. Problemas relacionados à DTA's são dificultados pela falta de notificação, pois poucos casos são registrados e relatados à Vigilância Sanitária. A minoria de casos que são relatados envolve a contaminação de várias pessoas ou descrevem indivíduos que possuíram quadros clínicos e sintomas prolongados.

As Doenças Transmitidas por Alimentos (DTA's) são causadas por microrganismos presentes em produtos alimentícios contaminados, que quando ingeridos causam injurias a saúde e ao bem estar do consumidor, provocando assim sintomas característicos 
como vômitos, diarréias e dores. Esses sintomas são mais graves e intensos quando observados em um grupo de risco, como idosos, grávidas e crianças, podendo causar até a morte do indivíduo ${ }^{14}$.

As bactérias são os principais microrganismos causadores de contaminação, sobretudo em alimentos, quando não se tem uma manipulação adequada e quando não se segue as boas $\operatorname{práticas}^{18}$. No presente estudo foram encontradas as bactérias do tipo Klebsiella spp., Escherichia coli. e Salmonella spp.

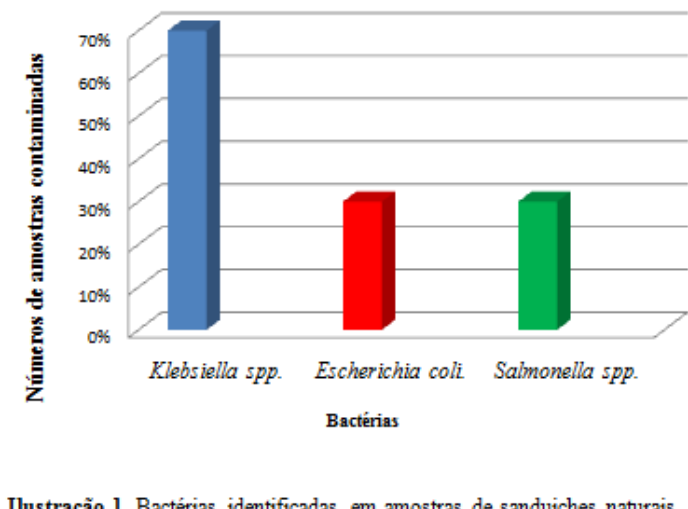

Nos resultados obtidos, pode-se observar que $70 \%$ das amostras apresentaram contaminação para Klebsiella spp. Segundo Matos ${ }^{19}$, a presença de Klebsiella spp. se dá pela transmissão desse microrganismos através do queijo, que é um dos componentes dos sanduíches naturais, estudos relacionados mostram que esse produto é um grande vinculador de microrganismos patogênicos. $\mathrm{O}$ autor ressalta que a transmissibilidade de microrganismo patogênico se da pela forma primitiva desde a obtenção do leite até o preparo artesanal do queijo.

No estudo observou-se a ocorrência de $30 \%$ de contaminação das amostras para Salmonella spp. De acordo com a Resolução RDC no 12 de 02 de janeiro de 2001, os alimentos devem ser ausentes deste tipo de bactéria $^{20}$.

Segundo Cardoso e Carvalho ${ }^{21}$, a Samonella spp., é um patógeno causador de enfermidades gastrointestinais e sua forma de transmissão principal é por alimentos contaminados. Esses microrganismos penetram nas células epiteliais através do estômago causando uma resposta inflamatória com sintomas como náuseas, vômitos, diarréia, febre entre outros.

A salmonelose é uma doença de notificação, pois a ocorrência de surtos é bastante significativa. De acordo com Marchi et al.,22 estudo sobre a ocorrência de surtos de doenças transmitidas por alimentos, constatou que a salmonelose foi a mais notificada no período de 1995 a 2007 com frequência de 53,2\%, sendo que em 2006 teve um índice de 30,3\% de notificação.

$\mathrm{O}$ consumo de maionese em conjunto com outros tipos de alimentos pode provocar surtos em seus consumidores. Segundo Valente e Peres ${ }^{23}$, cerca de $46 \%$ das pessoas analisadas em seus estudos foram contaminadas por Salmonella spp. decorrente do consumo da maionese, que é utilizada em conjunto com muitos alimentos inclusive o sanduíche natural.

Cerca de $30 \%$ das amostras analisadas foram positivas para Escherichia coli.que é um bastonete gram negativo, uma enterobactéria indicadora de contaminação fecal, sua presença em análise de alimentos pode significar que as Boas Práticas higiênicosanitárias não estão sendo seguidas. E. coli pode causar surtos de gastroenterites por ser altamente invasiva e destruir as micro vilosidades do intestino ${ }^{24}$.

Além da falta de higiene dos manipuladores a contaminação pode ser decorrente da composição do sanduíche natural, que possuem vegetais e hortaliças, como alface e tomate, e esses quando não higienizados corretamente são grandes transportadores de microrganismo, contaminando o alimento em questão.

Silva et al., ${ }^{25}$ em estudo sobre ocorrência de E.coli em vegetais e sua resistência a agentes de desinfecção de verduras verificou em suas análises que $13 \%$ se encontravam contaminadas por E.coli. Seu estudo ressalta que o hipoclorito e outros agentes desinfetantes são úteis na eliminação de E.coli quando colocado o vegetal em contato com esse produto. Portanto a manipulação e as boas práticas de higiene com cada produto que compõe o sanduíche natural é essencial para a qualidade do produto.

$\mathrm{Na}$ ilustração 2, encontra-se os resultados das análises fúngicas que foram observadas das amostras de sanduíches naturais. 


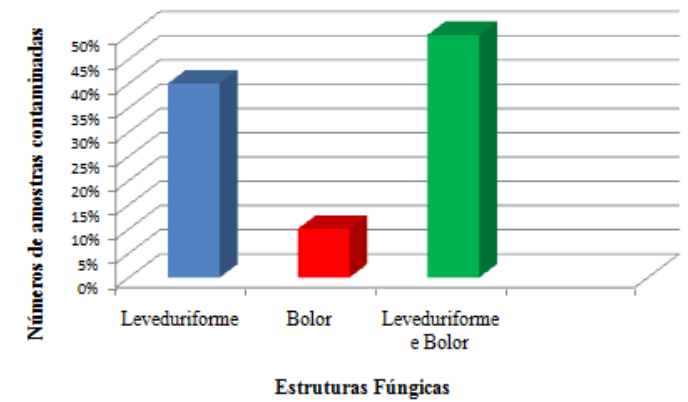

Ilustração 2. Formas micológicas encontradas nas amostras de sanduíches naturais analisadas.

Em $40 \%$ das amostras houve o crescimento de estruturas leveduriformes; $10 \%$ das amostras estavam contaminadas por fungos em forma de bolores e $50 \%$ estão contaminadas pelas duas formas fúngicas, bolores e leveduras.

De acordo com Silva, Capuano e Junior, ${ }^{26}$ as manifestações fúngicas na forma de leveduras encontradas em seus estudos foram do tipo onicomicoses em manipuladores de alimentos, sendo que $34,8 \%$ desses profissionais se encontram contaminados por micose. Lima, Rêgo e Montenegro, ${ }^{27}$ observaram $60 \%$ de contaminação fúngica em um estudo de espécies fúngicas isoladas a partir de unhas de manipuladores de alimentos, sendo a espécie mais encontrada a Cândida spp.

Segundo Maslinkiewicz e Freitas $^{28}$ as micotoxinas podem ser encontradas em muitos alimentos e ao serem ingeridos, por animais e homens, podem promover contaminação e causar inflamação do trato gastrointestinal, insuficiência renal, vômitos, intoxicação alimentar podendo levar a morte. Para evitar micotoxicoses, os alimentos devem ser bem acondicionados e higienizados, e não ser consumido aqueles produtos que forem de origem duvidosa.

Os resultados das análises parasitológicas através do método de Hoffman modificado das amostras de sanduíche natural foram de $40 \%$ para contaminação por Giardia spp.; $30 \%$ estavam contaminadas por Endolimax nana; $10 \%$ por Entamoeba coli e $40 \%$ das amostras estavam livres de contaminação parasitaria.

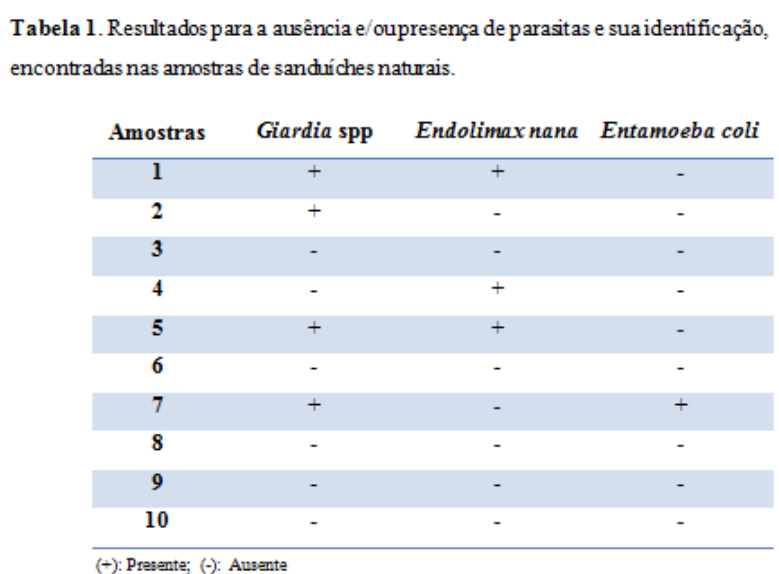

Em estudos sobre enteroparasitoses em manipuladores de alimentos, Carneiro ${ }^{29}$ obteve $81,25 \%$ de Entamoeba coli, ressaltando que esse resultado pode representar subsídios para ações futuras de controle de enteroparasitoses e o aprimoramento da educação higiênico- sanitária desses profissionais.

De acordo com Nolla e $\operatorname{Cantos}^{30}$, em seus estudos sobre a prevalência de enteroparasitas em manipuladores de alimentos, pode observar a ocorrência de 21,9\% de Endolimax nana, 18,5\% de Entamoeba coli e $11,8 \%$ de Giardialamblia em suas analises. Ressalta a grande necessidade de estudos como este para a observação e controle de parasitas em profissionais que possam transmitir microrganismos para alimentos pondo em risco a saúde da população.

\section{CONSIDERAÇÕES FINAIS}

Conclui-se que os resultados obtidos no presente estudo são de total importância para a regulamentação de normas e fiscalização de produção de alimentos e educação e regulamentação de manipuladores, a fim de favorecer assim as boas práticas de higiene evitando surtos e doenças transmitidas por alimentos.

\section{REFERÊNCIAS}

1. BAPTISTA, P; ANTUNES, C. Higiene e segurança alimentar na restauração - Volume II - Avançado. Forvisão - Consultoria em formação integrada, S.A. $1^{\circ}$ Edição. 300 Exemplares. 2005. 
2. MALlON, C; BORTOLOZO, E. A. F. Q. Alimentos comercializados por ambulantes: Uma questão de segurança alimentar. UEPG, Ponta Grossa. Ciência Biologia e Saúde, 10(3/4),65-76, 2004.

3. FAGUNDES, R. M. S. Verificação das boas práticas na produção de sanduíches em loja fast food, na cidade de Salvador-BA. Monografia apresentada ao curso de especialização em gestão da qualidade e vigilância sanitária em alimentos, Universidade Federal Rural do Semi-Àrido. Mossoró -2008.

4.PIRES, C.E.T. Principais bactérias presentes em doenças transmitidas por alimentos (DTA's). Trabalho apresentado como requisito parcial para graduação em Medicina Veterinária. UFRS. Porto Alegre 2012.

5.BRASIL, Ministério da Saúde, secretaria de Vigilância em Saúde, Departamento de Vigilância Epidemiológica: Manual integrado de prevenção e controle de doenças transmitidas por alimentos. 2010.

6. CARVALHO, I.T. Microbiologia dos alimentos. Programa Escola Técnica do Brasil. Ministério da Educação. DUFRPE, 2010.

7. SILVA, L.F. Procedimento operacional padronizado de higienização como requisito para segurança alimentar em unidade de alimentação. Dissertação de mestrado. Santa Maria-RS, Brasil, 2006.

8.DAMSCENO, K.S.F.S.C; ARDONHA, A.M.S. Perfil microbiológico de "sanduíches naturais" comercializados em Natal nas lanchonetes da universidade Federal do Rio Grande do Norte.Higiene Alimentar., v.13 (65), 47-50, 1999.

9.RODRIGUES, F.M.; VIROLI, S.L.M.; PAVLK, M.C.M.; SANDI, A.L.S. Avaliação das condições higiênico-sanitárias do comércio ambulante de alimentos na cidade de Paraíso do Tocantins. Revista ACTA Tecnológica - Revista Científica -v.5 (1), 2010.

10.SOUSA, P.C. Segurança alimentar e doenças veiculadas por alimentos: Utilização do grupo coliforme como um dos indicadores de qualidade de alimentos.Revista APS, v.9(1), 83-88,2006.

11.ALEIXO, J.A.G. RODRIGUES, K.L.; GOMES, J.P.; CONCEIÇÃO, R.C.S.; BROD, C.S.; CARVALHAL, J.B. Condições higiênico-sanitarias no comercio ambulante de alimentos em Pelotas-RS. Cienc.tecnol.aliment., Campinas, 23(3): 447-452, 2003.

12.FERRARI, C.K.B.; ASSUMPÇÃO. C.F.; MORZELLE. M.C.; FERRARI. G.S.L.; SOUZA. E. C. Avaliação microbiologica em alimentos de cantinas escolares na região do Médio Araguaia (MT/GO).Revista Baiana de Saúde Pública. v.37, n.1,45-56, 2013.

13. GENTA, T.M.S.; MAURÍCIO, A.P.; MATIOLI, G. Avaliação das Boas Práticas através de check-list aplicado em restaurantes self-service da região central de
Maringá, Estado do Paraná. Acta Sci. Health Sci. Maringá, v. 27, n. 2, 151-156, 2005.

14.BRASIL, Ministério da Saúde. Resolução RDC no 216, de 15 de setembro de 4004. Dispõe sobre o Regulamento Técnico de Boas Práticas para Serviços de Alimentos. D.O.U. 2004

15.SETER, L.; MICHIELIN, E.M.Z.; VIEIRA, M.A. Treinamento em higiene e boas práticas a colaboração de serviços de alimentação, em três municípios do oeste de Santa Catarina. Revista higiene alimentar. v.27, 222/223, 2013.

16. CAMPOS, M.C.B.; NICODEMO, T.C.; WEBER, M.L. Boas práticas em restaurantes do tipo self-service: situação no município de Alfenas, MG. Revista higiene alimentar. v.27, 222/223, 2013.

17.OLIVEIRA, A.B.A.; PAULA, C.M.D.; CAPALONGA, R.; CARDOSO, M.R.I.; TONDO, E.C. Doenças Transmitidas por Alimentos, principais agentes etiológicos e aspectos gerais: Uma Revisão. Revista HCPA. v.30, 279-285, 2010.

18.TORTORA, G.J.; FUNKE, B.R.; CASE, C.L. Livro de Microbiologia. Edição 10. Editora Artmed, 2012.

19.MATOS, L. M. Avaliação de boas praticas agropecuárias na ordenha sobre a qualidade do leite bovino, em propriedades produtoras de queijo artesanal serrano.Trabalho de conclusão em medicina veterinária da universidade federal do rio grande do sul. Porto alegre 2013

20. BRASIL. Ministério da Saúde. Resolução RDC $\mathbf{n}^{\mathbf{o}}$ 12 de 02 de janeiro de 2001. Aprova o regulamento técnico sobre padrões microbiológicos para alimentos. D.U.O. - Diário oficial da união; Poder Executivo, $10 \mathrm{de}$ janeiro de 2001.

21.CARDOSO, T.G; CARVALHO, V.M. Toxinfecção alimentar por Salmonella spp. Revista Instituto Ciência e Saúde, v. 24 (2), 95-101, 2006.

22.MARCHI, D.M.; BAGGIO, N.; TEO, C.R.P.A.; BUSATO, M.A. Ocorrência de surtos de doenças transmitidas por alimentos no Município de Chapecó, Estado de Santa Catarina, Brasil, no período de 1995 a 2007. Epidemiol. Serv. Saúde, Brasília, 20(3):401-407, jul-set 2011.

23.VALENTE, D.C.M; PERES, A.P. Análise de surto alimentar em um restaurante de um município do Paraná. Monografia do curso de Nutrição. 2011.

24.FRANCO, R.M. Escherichia coli: ocorrência em suínos abatidos na grande rio e sua viabilidade experimental em linguiças frescal tipo toscana. Tese de Mestrado apresentada ao programa de pós-graduação em Medicina Veterinária da Universidade Federal Fluminense. Niterói - Rio de Janeiro. 2002.

25. SILVA, N.; SILVEIRA, N.F.A.; YOKOYA, F.; OKAZAKI, M.M. Ocorrência de Escherichia coli em 
vegetais e resistência aos agentes de desinfecção de verduras. Cienc.tecnol.aliment, Campinas 23(2): 167173, 2003.

26.SILVA, J.O.; CAPUANO, D.M.; JUNIOR, E.G. Enteroparasitoses e onicomicoses em manipuladores de alimentos do município de Ribeirão Preto, SP, Brasil. RevBrasEpidemiol, 8(4); 385-92, 2005.

27.LIMA, K.M.; RÊGO, R.S.M.; MONTENEGRO. F. Espécies fúngicas isoladas a partir de unhas de manipuladores de alimentos. RBAC, vol. 39(3); 193196, 2007.

28.MASLINKIEWICZ, A; FREITAS, D.R.J. Micotoxinas: o que são e quais suas consequências para o homem. SB Rural, ed.87, ano 4, 2012.

29. CARNEIRO, L. C. Enteroparasitoses em manipuladores de alimentos de escolas publicas em Morrinhos - GO. Vita et Sanitas, v.1(1), 2007.

30. NOLLA, A.C.; CANTOS, G.A. Prevalência de enteroparasitoses em manipuladores de alimentos, Florianópolis, SC. Revista da sociedade Brasileira de Medicina Tropical38(6): 524-525, 2005. 